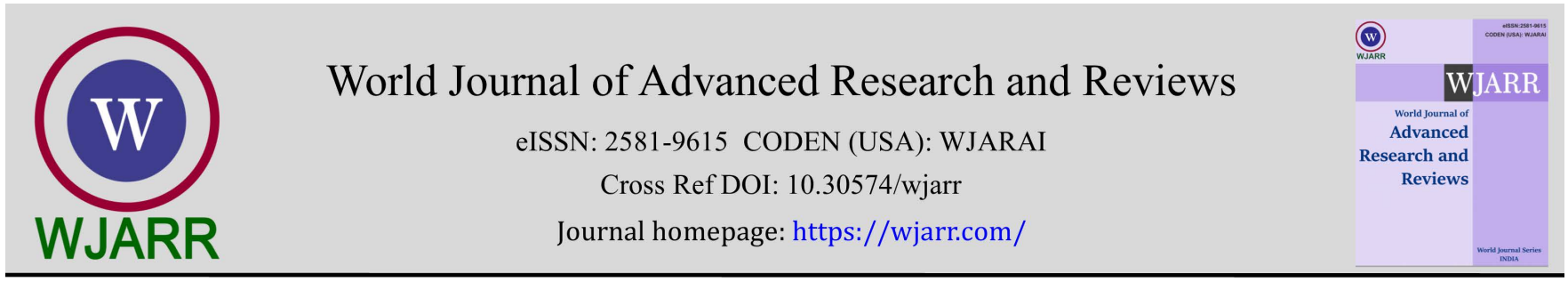

(RESEARCH ARTicle)

Check for updates

\title{
Microbial agglutination and lymphocyte blastogenesis potentials of isolated Achatina achatina snail lectin
}

\author{
Odiegwu C.N.C. ${ }^{1,}{ }^{*}$, Emenuga V. N. ${ }^{2}$, Ogamba S. E. ${ }^{3}$, Obi C. M. ${ }^{1}$ and Ejike C. E. ${ }^{4}$ \\ ${ }^{1}$ Department of Medical Laboratory Science, College of Health Sciences, Nnamdi Azikiwe University-Nnewi Campus, \\ Anambra State, Nigeria. \\ ${ }^{2}$ Department of Medical Laboratory Sciences, College of Medicine, University of Nigeria-Enugu Campus, Enugu State, \\ Nigeria. \\ ${ }^{3}$ Department of Medical Microbiology, Faculty of Medicine, College of Health Sciences, Nnamdi Azikiwe University, Nnewi \\ Campus, Anambra State, Nigeria. \\ ${ }^{4}$ Department of Medical Laboratory Science, College of Health Sciences, Chukwuemeka Odumegwu Ojukwu University, \\ Igbariam, Anambra State, Nigeria.
}

World Journal of Advanced Research and Reviews, 2021, 09(01), 104-113

Publication history: Received on 25 December 2020; revised on 03 January 2021; accepted on 05 January 2021

Article DOI: https://doi.org/10.30574/wjarr.2021.9.1.0505

\begin{abstract}
Lectins are involved in recognition phenomena and their ability to bind particular Carbohydrate structures are the key to their biological functions. Bacteria typically attaches to prospective host cell membranes in receptors with lectin like sugar specificity. This is of great importance as the adherence of bacteria to host tissue surfaces is the initial event in bacterial infection. Lectins are also known to play important roles in immune system by recognizing carbohydrates that are found exclusively on pathogens, or that are inaccessible on host cells. This ability of lectins to selectively bind or agglutinate specific sugars have made them useful tools for the characterization of certain cell types or fragments, to detect cells in different states of development, to distinguish normal from tumour cells and to separate different cell types by affinity chromatography. A total of 120 samples of local Achatina achatina snail specie were collected, authenticated at the Zoology Department of the University of Nigeria, Nsukka and 80mls of pooled crude Lectin extract was obtained. Purifications were performed on $20 \mathrm{mls}$ of the crude extract in three steps viz, Ammonium sulphate precipitation and Dialysis (Partial purifications), Con A Sepharose 4B affinity chromatography column (Complete purification). The affinity purified lectin was used in all the tests conducted in this research. The crude, partially and complete/affinity purified lectin extracts were subjected to Haemagglutination and Protein Assay tests. The Molecular weight was deduced by Sodium dodecyl sulphate polyacrylamide gel electrophoresis (SDS-PAGE) method. The microbial agglutination potentials of the lectin was assessed by testing typed bacterial organisms viz, Salmonella typhimurium, Escherichia coli, Lactobacilli acidophilus, Pseudomonas aeruginosa, Staphylococcus aureus, Klebsiella aeruginosa and four typed fungal organisms: Aspergillus niger, Trichophyton mentagrophytes, Candida albicans and A. flavus. The lectin's Lymphocyte blastogenesis activities was determined by its incubation with human lymphocytes for mitogenic stimulation assay. The results of the research showed as follows: On complete/affinity purification, $15 \mathrm{mls}$ of pure sample containing only the high molecular weight lectin was obtained. On standardization, the respective haemagglutination tests on the crude, partially and affinity purified lectin showed preferential agglutinations with Blood group A type. Only $S$. typhimurium $(+++)$, E. coli $(+)$ and L. acidophilus $(+)$ reacted with the lectin but in different strengths. Incubation of the lectin with lymphocytes from human serum showed that it has the ability to stimulate lymphocytes to undergo mitosis. This research has therefore succeeded in assessing the Microbial agglutination and Lymphocyte blastogenesis potentials of the isolated and characterised A. achatina snail lectin.
\end{abstract}

Keywords: Achatina achatina Lectin Microbial Agglutination and Lymphocyte Blastogenesis potentials.

${ }^{*}$ Corresponding author: Odiegwu C.N.C.

Department of medical lab. Science, college of health sciences, nnamdi azikiwe university-nnewi campus, anambra state, nigeria.

Copyright @ 2021 Author(s) retain the copyright of this article. This article is published under the terms of the Creative Commons Attribution Liscense 4.0. 


\section{Introduction}

Lectins recognize specific sugars on cell surface and if they match, bind to that particular sugar. Agglutination caused by lectins is inhibited by a specific sugar. This characteristic distinguishes lectins from antigens which are produced by animals. A lectin usually contains two or more binding sites for carbohydrate units. The carbohydrate-binding specificity of a certain lectin is determined by the amino acid residues that bind the carbohydrate. Because of the tremendous diversity of carbohydrate-binding specificities among lectins, some researchers classify them according to the small carbohydrate haptens they recognise, example, galactose-binding lectins or GlcNAc-binding lectins [1].

Some viruses use lectins to attach themselves to the cells of the host organism during infection. Lectins may be disabled by specific mono and oligosaccharides, which bind to them and prevent their attachment to cell membranes [2]. Similarly, some bacteria like Salmonella and Escherichia coli carry several surface lectins with pronounced immune suppressive ability. Both adhere to epithelial cells by attaching to the sugar mannose on the victim's cells surface [3].

Lectins are extremely sensitive to subtle structural differences among bacteria isolates, and lectin typing allows for differentiation of a greater number of groups than sero typing. The technique, whether used independently or in conjunction with sero typing, is of considerable potential value both for epidemiological studies and for routine clinical diagnosis. Lectin agglutination assays are rapid, inexpensive and reproducible, and lectins are stable and easy to store, readily available from major suppliers and active at low concentrations [4].

Most lectin tests for identification of bacterial pathogens are based on selective agglutination reactions. Generally, a colony of an initial culture medium is suspended in a buffer solution at a sufficiently high cell density, and then mixed with the lectin. Agglutination is taken as evidence of the presence of the pathogen in question. For instance, the use of lectins in combination with conventional enzymatic tests has enabled fast testing or selective detection of the species of the family Neisseriaceae. Also, by means of simple agglutination reactions using lectins, the bacterium Staphylococcus aureus can be differentiated from the coagulase negative staphylococci etc. Microbial surfaces bear many of the sugar residues capable of interacting with lectins. Indeed, any surface-exposed sugar is a potential lectin-binding site. The ability of lectins to react with microbial glyco-conjugates means that it is possible to employ them as sorbents for whole cells, and this feature together with their extreme specificity makes them useful tools for identification of bacteria [4]. Also, in some cell types, some lectins for example, H.pomatia conjugates have been shown to be as effective as monoclonal antibodies for the detection and differentiation of herpes simplex virus type 1 and 2 (HSV - 1 and HSV - 2) in culture cells [5].

Complex oligosaccharide structures displayed at cell surfaces incorporated into the extracellular matrix and attached to secreted glyco-proteins can serve structural roles, mediate movement of glyco- conjugates to the cell surface or act as markers that mediate cell - cell and cell matrix recognition events. The non-structural roles of sugars generally require the participation of sugar-binding lectins. Because of the ability of lectins to identify and distinguish carbohydrate determinants in human blood cells, they are of immense importance in agglutination of cells and blood typing [6].

Some lectins have been discovered to be mitogenic in that they have the ability to stimulate lymphocytes to undergo mitosis. Mitogenic stimulation is the result of binding of lectins to sugars on surfaces of the lymphocytes [7]. Mitogenic lectins have been found as indispensable tools for the study of signal transmission into cells and for the analysis of the biochemical events that occur during lymphocyte stimulation in vitro [8]. This property of lectins has been exploited extensively in an attempt to understand the process of lymphocyte blastogenesis and the biochemical and structural alterations associated with mitogenesis [9]. Some lectins when bound to sugar moieties in cell walls or lymphocyte membrane change the physiology of the membrane to cause mitosis-multiplication or division of a cell forming two daughter cells. Mitogenic stimulation by lectins provides an easy and simple means to assess the immuno-competence of patients suffering from diversity of diseases, recently also in AIDS. This is also used to monitor the effects of various immune suppressive and immune therapeutic manipulations. It is also employed for the preparation of chromosome maps for karyotyping, sex determination and detection of chromosomal defects. Examples of lectins with such mitogenic properties include PHA and Con A (T-lymphocytes stimulation) and Poke Weed mitogen (B-lymphocyte stimulation) [10].

Thus, this research is designed with a view to finding out the potentiality of the A. achatina lectin to bind specifically to these sugar residues on the cell wall of bacteria and also on fungi (yeasts) clinically isolated from humans via agglutination. This is based on the fact that lectins are non-immune protein that have sugar specificity varying from mannose, galactose, $\mathrm{N}$-acetyl glucosamine, $\mathrm{N}$-acetyl neuramic acid which is the basis of their classification according to the monosaccharide which is the most effective inhibitor of agglutination of erythrocytes by lectins. Due to the 
numerous end uses applications of lectins and the need to produce at cheaper rate indigenous reagents from local sources for routine diagnosis of many disorders including agglutination and identification studies inform the basis of embarking on this work. The specific objectives of this research are to: 1. Isolate/Extract Achatina achatina snail lectin (a local snail specie). 2. Purify the crude Achatina achatina snail extract. 3. Deduce the Protein contents and Molecular weight of the snail lectin. 4. Determine the effects of the A. achatina lectin on typed Bacterial and Fungal organisms. 5. Assess the lymphocyte blastogenesis potentials of the snail lectin. 6. To explore the commercial viability of the $A$. achatina lectin.

\section{Material and methods}

One Hundred and Twenty (120) samples of the local Achatina achatina snail (Ejuna Ojii) were collected for analysis. Their albumin glands were obtained by methods of Kristensen and Frandsen, 1984, [11] weighed and extracted according to the methods of Hammarstrom and kabat, 1969 [12]. The crude extracts were mixed with sodium azide preservative and stored frozen at $-20 \mathrm{oC}$ ready for use.

\subsection{Purification of the Crude Extracts}

The crude A. achatina extracts were purified employing: A. Ammonium Sulphate Precipitation. B. Dialysis and C. Affinity Chromatography purification methods and were carried out based on the following principles:

\subsubsection{Ammonium sulphate precipitation method}

This is a simple and effective means of fractionating proteins and is based on the fact that at high salt concentrations the natural tendency of proteins not to aggregate is overcome, since the surface charges are neutralized. Charge neutralization means that proteins will tend to bind together, form large complexes and hence are easy to precipitate out by mild centrifugation.

\subsubsection{Dialysis method}

Dialysis is a classic laboratory technique that relies on selective diffusion of molecules across a semi-permeable membrane to separate molecules based on size.

\subsubsection{Affinity chromatography method}

The Affinity Chromatography column of choice used in this research for the purification of the Achatina achatina lectin is Con A Sepharose 4B (HiTrap Con A 4B). Con A Sepharose 4B is a chromatography medium for separation and purification of glyco-proteins, polysaccharides and glyco-lipids. Con A Sepharose is an affinity medium with Concanavalin A (Con A) coupled to Sepharose 4B by the cyanogens bromide method. HiTrap Con A can be operated with a syringe, a peristaltic pump or a liquid chromatography system such as AKTA design [13].

\subsection{Method of analysis}

Agglutination tests were carried out on the crude, partially purified and affinity chromatography purified extracts using scrupulously cleaned precipitation tubes in the standard tube technique and examined macroscopically and microscopically. The separately pooled and washed human ABO cells were washed four times in saline, and 5\% suspension of the cells were made and used for the agglutination tests both in the control test and actual tests as follows:

\subsubsection{Control test}

Equal volumes of the commercially prepared anti-sera were mixed with separately pooled and washed human ABO cells and examined after five (5) minutes at room temperature.

\subsubsection{Actual test}

Equal volumes of the crude, ammonium sulphate, dialysed, (partially purified) and Affinity purified (Completely purified) Achatina achatina snail extracts were each separately mixed with the separately pooled and washed human ABO cells and their reactions examined macroscopically and microscopically. The crude extract, ammonium sulphate, dialysed and Affinity purified extracts were subjected to protein assay using Pierce BCA Protein Assay Kit method.

\subsection{Protein assay of the crude, partially purified and affinity purified $A$. achatina Extracts}




\subsubsection{Extracts Protein Assay Using Pierce BCA Protein Assay Kit Method (Thermo Scientific)}

The Thermo Scientific Pierce BCA Protein Assay is a detergent-compatible formulation based on bicinchoninic acid (BCA) for the colorimetric detection and quantification of total protein. This method combines the well-known reduction of $\mathrm{Cu}++$ to $\mathrm{Cu}+$ by protein in an alkaline medium (the biuret reaction) with the highly sensitive and selective colorimetric detection of the cuprous cation $(\mathrm{Cu}+)$ using a unique reagent containing bicinchoninic acid. The purplecoloured reaction product of this assay is formed by the chelation of two molecules of BCA with one cuprous ion.

\subsubsection{Preparation of standards and working reagent}

Preparation of diluted albumin (BSA) standards

- The dilution scheme for standard test tube and micro plate procedures, the working range of 20-2000ug/ml was chosen because the isolated lectin is supposed to be a high molecular weight protein. Thus, various concentrations of the BSA standards were prepared or diluted using Phosphate buffered saline diluents in test tubes.

- The various concentrations of the BSA standards were properly mixed using Vortex Genie 2 and transferred into micro plate wells by means of automatic pipettes.

- Thereafter, the Pierce BCA protein assay reagents A and B were mixed together in a separate clean tube in a ratio of 50 volumes of reagent A to 1 volume of reagent B. Using automatic pipettes, 200uL of the working BCA reagents mixture were transferred into the micro plate wells containing the various concentrations of the BSA standards $(\mathrm{A}-\mathrm{I})$ and the lectin extract sample under assay.

- The samples in the micro plate wells were rocked to mix and incubated at $37^{\circ} \mathrm{C}$ for 30 minutes and protein content viewed and estimated.

- At the end of the incubation period, the micro plates contents were read using Varioskan Flash UV/Visible and Flourescence Spectrophotometer (Micro plate reader).

- The absorbance values for the BSA standards and sample(s) were deduced and plotted, the absorbance on the vertical axis and BSA standard concentrations on the horizontal axis.

- By using the equation: $\mathrm{Y}=0.0009 \mathrm{X}+0.1205, \mathrm{X}$ (which is the concentration of the unknown) can be calculated.

\subsection{Determination of the Molecular weight of the Affinity Purified Achatina achatina Snail Lectin}

The analytical techniques of Soduim Dodecyl Sulphate Polyacrylamide Gel Electrophoresis (SDS - PAGE), Gel filtration, Ultracentrifugation etc are all important in obtaining or isolating a pure protein including its molecular weight determination. However, SDS - PAGE is usually the first choice as an assay of protein purity due to its reliability and ease. The presence of SDS and the denaturing step causes proteins to be separated approximately based on size, although aberrant migration of some proteins may occur. Also, different proteins may stain differentially. Therefore, the SDS-PAGE technique is the method of choice used in this research for the determination of the molecular weight of the Achatina achatina snail lectin.

Principles of SDS - PAGE: An electric field is applied across the Gel, causing the negatively charged proteins to migrate across the Gel towards the positive (+) electrode (anode). Depending on their size, each protein will move differently through the Gel matrix: Short proteins will be more easily fit through the pores in the Gel; while larger ones will have more difficulty (they encounter more resistance). After a set amount of time (usually a few hours - though this depends on the voltage applied across the Gel; higher voltages run faster but tend to produce somewhat poorer resolution), the proteins will have differentially migrated based on their size; smaller proteins will have travelled further down the Gel, while larger ones will have remained closer to the point of origin. Proteins may therefore be separated roughly according to size (and thus molecular weight); however, certain glyco-proteins behave anomalously on SDS Gels [14].

\subsection{Determination of Microbial Agglutination Properties of the Affinity Purified A. achatina Snail Lectin}

Lectins are extremely sensitive to subtle structural differences among bacteria isolates, and lectin typing allows for differentiation of a greater number of groups than sero typing. The technique, whether used independently or in conjunction with sero typing, is of considerable potential value both for epidemiological studies and for routine clinical diagnosis [4].

\subsubsection{Bacterial Agglutination with the Affinity Purified A. achatina Lectin}

The bacteria organisms used include: Salmonella typhimurium, Pseudomonas aeruginosa, Klebeiella aeruginosa, Staphylococcus aureus, Escherichia coli and Lactobacilli acidophilus. 


\subsubsection{Procedures}

- $\quad$ The organisms were grown on nutrient agar at $37^{\circ} \mathrm{C}$ for eighteen (18) hours.

- Thereafter, a loop full of thick phosphate buffered saline (PBS) emulsion of each organism was tested for agglutination on a microscopic slide against the purified A. achatina lectin.

- Two (2) other slides were set up containing (a) Phosphate buffered saline (PBS) and the purified lectin.

- (b) Phosphate buffered saline (PBS) and a loop full of a thick emulsion of each organism. Steps 3a.and b above served as the negative and auto - agglutination controls respectively.

- The set ups were observed macroscopically for agglutination reactions and graded,,++++++ according to the method of Drabar et al., 1978 [15].

\subsubsection{Fungal Agglutination with the Affinity Purified A. Achatina Lectin}

The mycotic organisms used were: Candida albicans, Aspergillus niger, Trichophyton mentagrophytes and Aspergillus flavus.

\subsubsection{Procedures}

The procedures are as stated above for bacterial agglutination testing.

\subsection{Assessment of Lymphocyte Blastogenesis Potentials of the Affinity Purified A. achatina Lectin}

Incubation of lymphocytes with very low concentrations of certain lectins $(1-5 \mathrm{mg} / \mathrm{ml})$ has been found to induce them to grow and divide [16]. Mitogenic stimulation is a key event in immune response of the body against foreign agents. Some lectins have been discovered to be mitogenic in that they have the ability to stimulate lymphocytes to undergo mitosis. Mitogenic stimulation is the result of binding of lectins to sugars on surfaces of the lymphocytes [7].

\subsubsection{Procedures}

- Mix equal volumes of serum with the appropriate concentration of the affinity purified A. achatina snail lectin.

- Incubate the mixture at $37^{\circ} \mathrm{C}$ for 1 hour.

- Transfer a drop on a microscope slide and view under the microscope.

- Make a smear or film of the mixture and stain with Leishman stain.

- Examine using x100 oil immersion objectives.

\section{Results and discussion}

The results of the analysis obtained in this research are as illustrated below in Figures 1, 2, 3, 4, 5 and Table 1. Figures 1 and 2 represent the Haemagglutination patterns of the A. achatina lectin in saline control and with Blood group A Cells respectively. Figure 3 is the Bicinchoninic acid (BCA) Protein Calibration curve performed with Bovine Serum Albumin. Figure 4 is the SDS-PAGE migration bands patterns of the crude, partially purified and the affinity/completely purified A. achatina lectin compared with the known molecular weight markers/standards. Table 1 shows the Bacterial and Fungal organisms' agglutination patterns with the affinity purified A. achatina lectin. Figure 5 is the Photomicrograph showing mitotic induction of Lymphocytes by the incubated and stained human serum and the Affinity Purified $A$. achatina snail lectin mixture. The results of the Research are as shown below: 


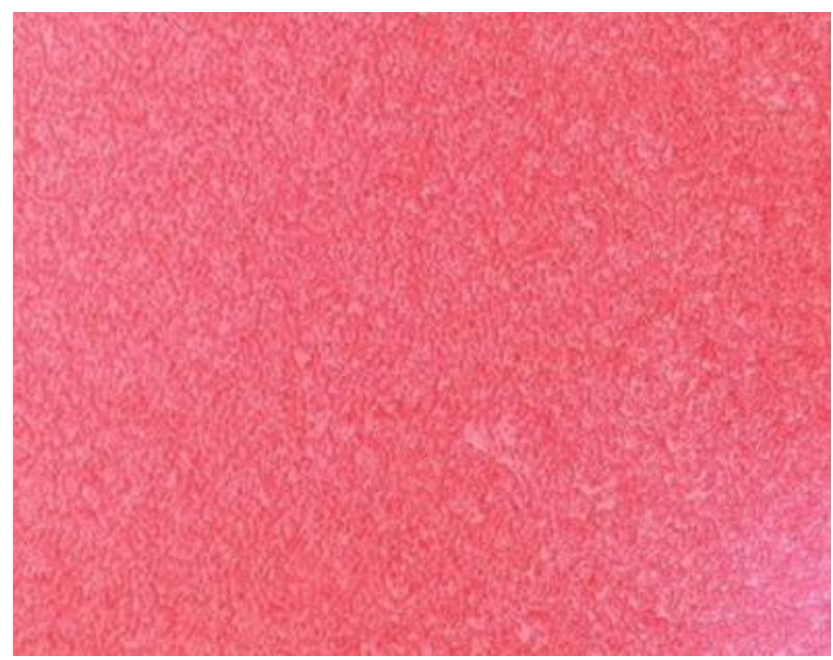

Figure 110 x Photomicrograph of phosphate buffered saline haemagglutination negative control.

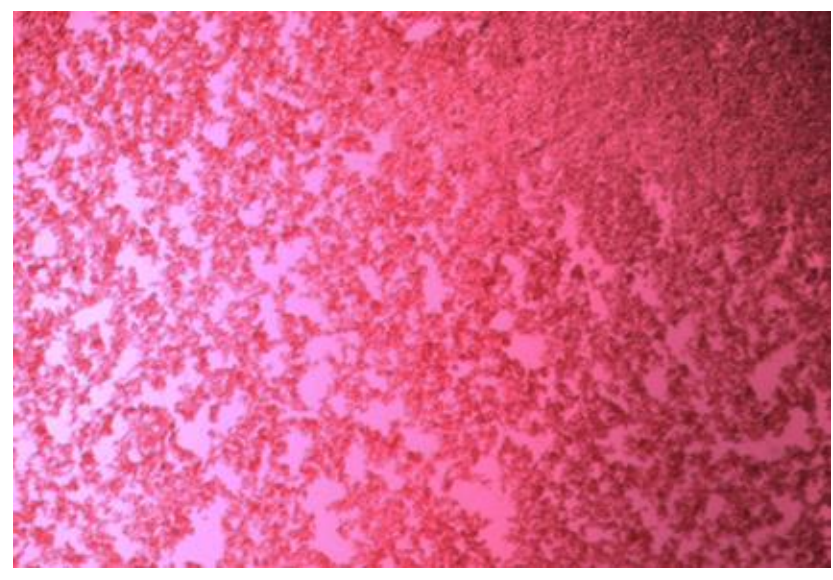

Figure 210 x Photomicrograph haemagglutination pattern of the Achatina achatina lectin with human blood group A cells.

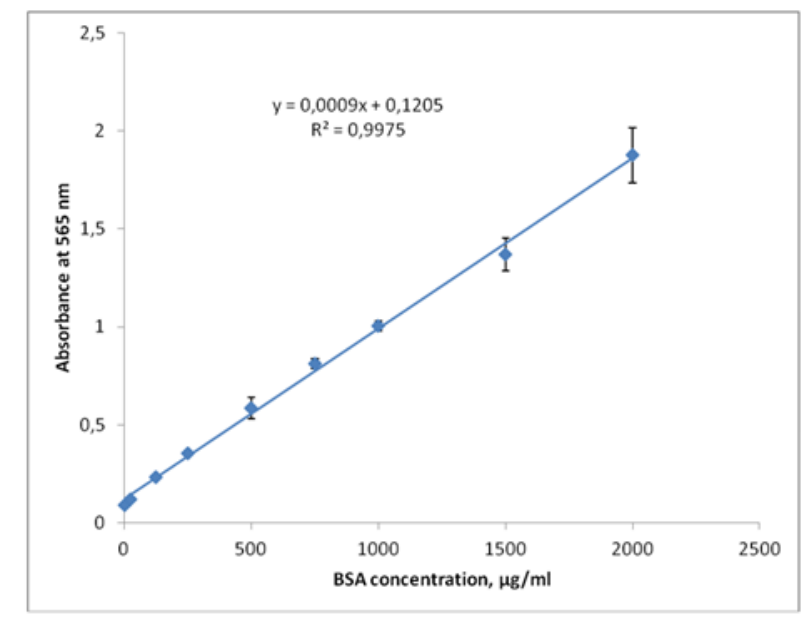

Figure 3 BCA protein calibration curve performed with BSA standards

Samples were analysed neat and diluted 10 times. The neat samples were too concentrated and could not be used to calculate the protein content. The samples were diluted ten times after fitting the absorbance values to the calibration 
curve (and multiplication by 10), the following concentrations were found: Crude $=13.5 \mathrm{mg} / \mathrm{ml}$; Dialysed Precipitate = $5.7 \mathrm{mg} / \mathrm{ml}$; Dialysed Supernatant $=5.0 \mathrm{mg} / \mathrm{ml}$ and Affinity Purified $=0.422 \mathrm{mg} / \mathrm{ml}$.

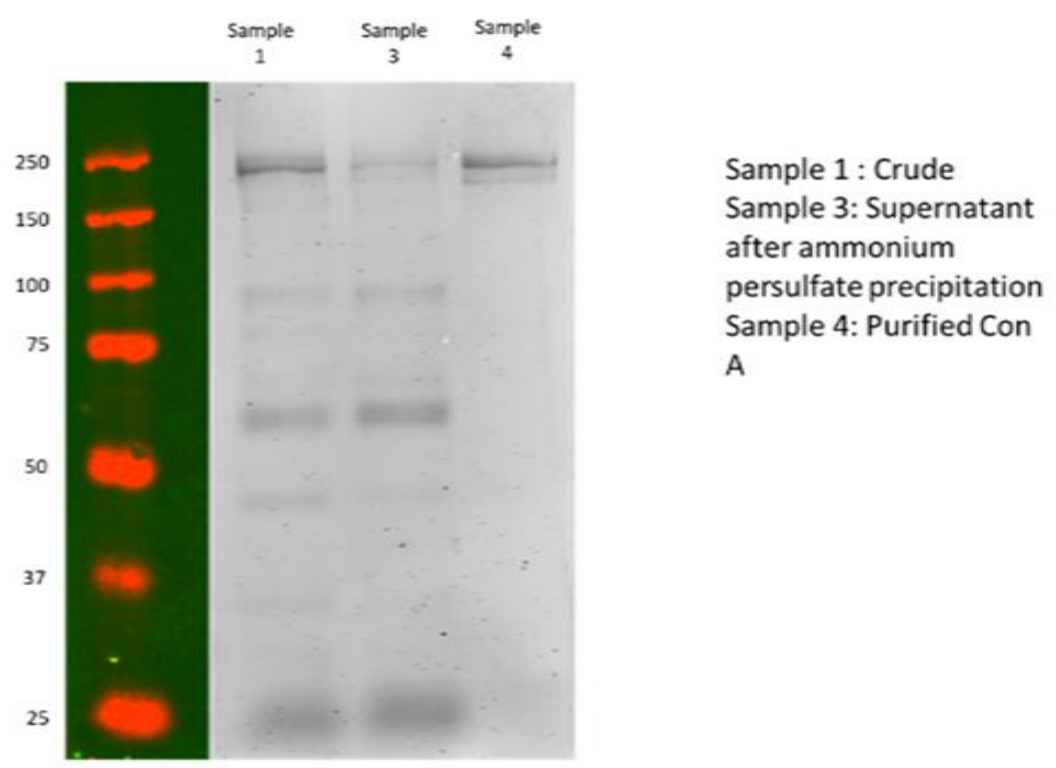

Figure 4 The SDS-PAGE migration bands patterns of the crude, partially purified and affinity/completely purified A. achatina lectin compared with the known molecular weight markers/standards.

Table1 The bacterial and fungal agglutination patterns with the affinity purified Achatina achatina snail lectin.

\begin{tabular}{|c|c|c|c|c|}
\hline S/no & Name of organism & $\begin{array}{c}\text { Agglutination } \\
\text { Pattern with } \\
\text { the lectin }\end{array}$ & Negative control & $\begin{array}{c}\text { Autoagglutination } \\
\text { control }\end{array}$ \\
\hline 1. & Klebsiella aeruginosa & - & - & - \\
\hline 2. & Escherichia coli & + & - & - \\
\hline 3. & $\begin{array}{l}\text { Staphylococcus } \\
\text { aureus }\end{array}$ & - & - & - \\
\hline 4. & $\begin{array}{l}\text { Pseudomonas } \\
\text { aeruginosa }\end{array}$ & - & - & - \\
\hline 5. & $\begin{array}{l}\text { Salmonella } \\
\text { typhimurium }\end{array}$ & +++ & - & - \\
\hline 6. & $\begin{array}{l}\text { Lactobacilli } \\
\text { acidophilus }\end{array}$ & + & - & - \\
\hline 7. & Aspergillus niger & - & - & - \\
\hline 8. & Candida albicans & - & - & - \\
\hline 9. & $\begin{array}{l}\text { Trichophyton } \\
\text { mentagrophytes }\end{array}$ & - & - & - \\
\hline 10. & Aspergillus flavus & - & - & - \\
\hline
\end{tabular}




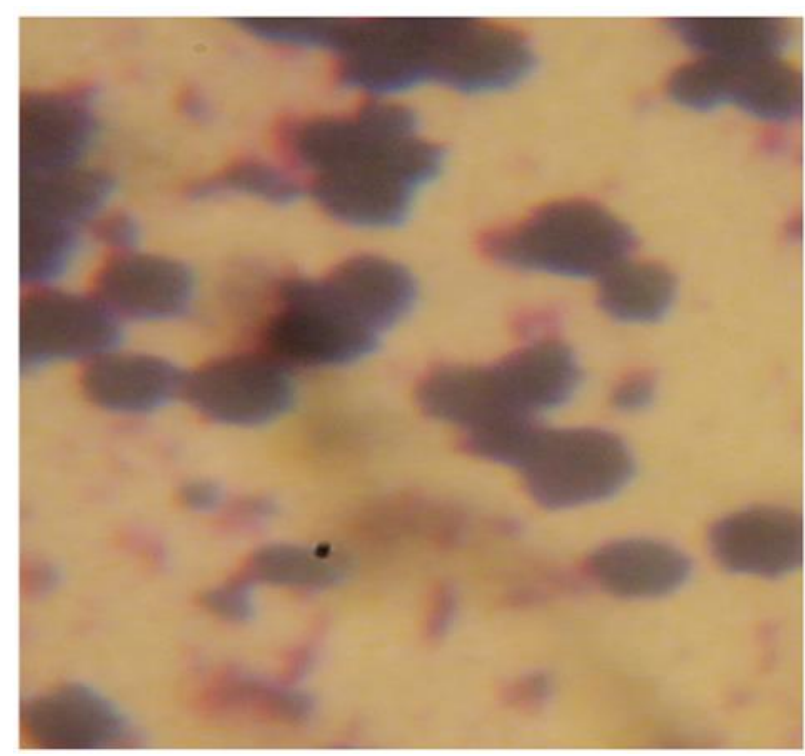

Figure5 Photomicrograph showing mitotic induction of Lymphphocytes by the incubated and stained human serum and the affinity purified $A$. achatina lectin mixture.

\section{Discussion}

In general, lectins bind to sugar moieties in cell walls or membrane, thereby change the physiology of the membrane to cause agglutination, mitosis or other biochemical changes in the cell [3]. Mitogenic stimulation is the result of binding of lectins to sugars on surfaces of the Lymphocytes [7]. Lectins have proved useful for epidemiological characterization of pathogens. For instance, an agglutination procedure for the identification/ typing of Bacillus anthracis using lectins from Soy bean (SBA) and the snail Helix pomatia (HPA) has been developed [4]. In these connections, the findings from this research have some similarities and differences in applications with the works referenced above and others.

Haem-agglutination activity assay was performed on the A. achatina snail extract. The colorimetric detection and quantification of total protein content of the lectin was carried out by means of Thermo Scientific Pierce BCA Protein Assay which is a detergent-compatible formulation based on bicinchoninic acid (BCA) and the lectin's molecular weight was determined using SDS-PAGE electrophoretic mobility band pattern.

The results obtained from this research showed as follows: The Crude, Ammonium sulphate precipitate, Dialysed and Affinity Chromatography purified A. achatina lectin extracts, all reacted with human blood group A type. However, all the investigations carried out in this research were performed using the affinity purified lectin because it gave improved reactivity and is free from other proteins or contaminants except the A. achatina glyco-protein of interest. In this way, results derived therein could rightly be attributed to the snail lectin. The Phosphate buffered saline negative control and the Haem-agglutination pattern of the lectin with human blood group A cells respectively are shown in Figures 1 and 2. This activity assay depicts the A. achatina lectin extract as a glyco-protein with lectinic properties which is quite in agreement with the works of Tsutsui et al., 2003 [17], Ito et al., 2011 [18]. The Bicinchoninic acid (BCA) Protein Calibration curve performed with Bovine Serum Albumin and the SDS-PAGE migration bands patterns of the crude, partially purified and the affinity/completely purified A. achatina lectin compared with the known molecular weight markers/standards are illustrated in Figures 3 and 4. The findings deduced in Figures 3 and 4 are in line with the works of Tsutsui et al., 2003 [17] and Ito et al., 2011 [18].

The Agglutination patterns of the Bacterial and Fungal organisms tested are displayed in table 1. Out of the ten (10) micro-organisms assessed, only Salmonella typhimurium, reacted strongly (+++) with the affinity purified lectin. Escherichia coli and Lactobacilli acidophilus reacted rather weakly $(+)$ with the Lectin and thus specificity with Salmonella typhimurium could be achieved by standardization.

The other bacterial organisms viz, Staphylococcus aureus, Klebsiella aeruginosa and Pseudomonas aeruginosa reacted negatively with the lectin. Also, the four (4) Fungal organisms tested viz, Aspergillus niger, Trichophyton mentagrophytes, Candida albicans and Aspergillus flavus all gave negative agglutination patterns with the A. achatina lectin. 
The Photomicrograph showing the induction of mitosis in lymphocytes by the incubated and stained mixture of the lectin with human serum is expressed in Figure 5. This shows similarity with the works of Nowell, 2008 [7]. Also, the results of the microbial agglutination patterns support the works of Munoz-Crego et al., 1999 [4]; Drabar et al., 1978 [15] etc

\section{Conclusion}

The research findings show that the Achatina achatina snail extract demonstrated lectinic properties as it reacted with human erythrocytes and the affinity purified snail lectin was found to be a high molecular weight protein with protein content of $0.422 \mathrm{mg} / \mathrm{ml}$ and molecular weight of $250 \mathrm{kDa}$. These and other findings including its relative selective microbial agglutination pattern, mitotic induction of lymphocytes etc., classify the A. achatina snail extract as a lectin and with useful end uses applications. Since this lectin demonstrated some positive end uses applications as established in this research and more that may be shown in further researches on it, makes the lectin viable for commercial production. This research has therefore succeeded in assessing the Microbial Agglutination and Lymphocyte Blastogenesis Potentials of the Isolated and Characterised $A$. achatina Snail Lectin.

Recommendations

In view of the findings deduced from this research including those cited in the literature, the importance and end uses applications of lectins, A. achatina lectin inclusive in Molecular Biology, Biomedical and Life Sciences cannot be over emphasized. Therefore, it is hereby recommended that further research activities on this and other local animal and plant lectins be intensified with a view to commercially producing local or indigenous lectin products that could serve as an adjunct or potent agents for treatments, routine diagnosis of many health disorders including agglutination and identification studies.

\section{Compliance with ethical standards}

This research is in full compliance with ethical standards and moreover, human participants or subjects were not used while conducting this research.

\section{Acknowledgments}

We hereby acknowledge the Tertiary Education Trust Fund (TETFund) of Nigeria for the Research grant Awarded to the corresponding Author that made possible the comprehensive analysis of this snail lectin to be conducted at the Department of Advanced Diagnostics and Biosensors, Cranfield University, Cranfield, Bedfordshire, England, United Kingdom. This is because, this research has many limitations including locally unavailable, scarce or very expensive molecular equipment, chemicals, reagents, expertise etc, but through the TETFund Research grant intervention, the objective of this research was achieved. Thus, we appreciate the corresponding author Re: Dr. C.N.C. Odiegwu for the judicious use of the TETFund grant including payment of the Bench Fees to Cranfield University, which enabled the provision of the much needed expertise, supervision, technology, equipment etc. by the Cranfield University, Cranfield, Bedfordshire, England, United Kingdom.

\section{Disclosure of conflict of interest}

There is no conflict of interest amongst the authors as all the authors contributed in one way or the other in conducting the research and in writing the manuscript which was eventually articulated and submitted for publication by the corresponding author.

\section{References}

[1] Cs. Stedwards. Edu. Lectin Structure, Function and Control. 2011. Accessed, 5 th $^{\text {May, }} 2011$.

[2] Natural Therapy Pages.com. Lectins and Nutrition. 2011. Accessed, 12 ${ }^{\text {th }}$ May, 2011.

[3] Dadamo P. Link Informatics for Lectins. Journal of biological sciences. 2008; 8, 17 - 24.

[4] Munoz-Crego A., Alvarez O., Alonso B., Rogers D.J., Llovo J. Lectins as diagnostic probes in clinical bacteriologyAn overview. Lectins, Biology, Biochemistry, Clinical Biochemistry. 1999; 13, 139 - 157.

[5] Molocular Probes. Lectins and other Carbohydrate - Binding proteins. 2004. Htt://www.probes.com/handbook/sections/0707.html.

[6] Interchim. Lectin list. 2010.http://www. Interchim fr/fr/m/msqo 22.pdf. 
[7] Nowell P.C. Phytohaemagglutinin as initiator of mitosis in culture of normal human leucocytes. Calicut. Medical Journal. 2008; 6(1), 2-11.

[8] Hamblin J., Kent S.P. Possible role of Phytohaemagglutinins in Phaseolus vulgaris. New Biol Med. of Science, Medline. 1973; 245, 28-30.

[9] Vector Laboratories. Lectins. Orton Southgate, Peterborough, PE 26XS, England. 2004; 1-2.

[10] Krispin S. C. (2008). The lectin report. Churchill Livingstone, Edinburgh, U.K. 2008; 35 - 40.

[11] Kristensen T. K., Frandsen F. Methodology for Snail Dissection and Preparation. WHO - Danish Bilharziasis Laboratory Journal. 1984; Vol II, 5-8.

[12] Hammerstrom S., Kabat E. A. Purification and Characterization of a Blood group A. Re-active Haemagglutinin from the Snail Helix pomatia and a Study of its Combining Site. Biochemistry. 1969; 8, 2696 - 2705.

[13] GE Healthcare Bio-sciences 2014. HiTrap Con A 4B Affinity Columns Instructions. www.gelifesciences.com/protein-purification. Wikipedia.org. 2011. SDS-PAGE. Accessed 17th October 2011.

[14] Drabar P., Virklicky V., Lengerova A. Role of Cell-cell Interaction in Mitogenic Stimulation of Lymphocyte I. Dissociation of Concanavalin A-inducible Lymphocyte Activation and Agglutination. J. Immunogen. 1978; 5, 6770.

[15] Disabeto G., Nall J.N., Thompson L. T-cell mitogens and Polyclonal B-cell Activators. Method Enzymol. 1987; 150, $3-17$.

[16] Tsutsui, S., Tasumi S., Suetake H., Suzuki Y. Lectins Homologous in those of Monocotyledonous Plants in the Skin mucus and Intestine of Pufferfish, Fugu rubripes. Journal of Biological Chemistry. 2003; 278, 20882-20889.

[17] Ito S., Shimizu M., Nagatsuka M., Kitajima S., Honda M., Tsuchiya T., Kanzawa N. High Molecular Weight Lectin Isolated from the Mucus of the Giant African Snail Achatina fulica. Biosci. Biotechnol. Biochem. 2011; $75(1), 20$ 25 . 